\title{
OPNETによるモデリングと性能評価方法
}

Introduction of Modeling and Performance Evaluation Using OPNET

\author{
山田博司 ${ }^{\dagger}$ \\ Hiroshi Yamada
}

Sunmany

ネットワークシミュレーションツールのOPNET につ いて, モデリング, 利用方法に関する基本事項を説明する. 対象として, ネットワークシステムの設計・管理, 及び, プロトコル・ネットワークの研究開発を担当し, OPNET を利用している，または，これから利用してみようと考 えているエンジニアを想定する．まず，OPNETの背景と なる仮想 NW 環境の概念と OPNET ッールの全体像につ いて述べる. 次に, OPNET を用いたルーチングァーキテ クチャ評価の基本的な方法を述べる. 最後に, プロトコ ルモデル開発用ツールである OPNET Modeler の基本的な 使い方について解説する.

\section{LG] woris}

OPNET, シミュレーション, IP ネットワーク, プロトコル

\section{1. まえがき}

IP (Internet Protocol) ネットワーク (以後 NW と記す) サービスは, 様々なプロトコルの上で動作している。大 きな IPNW であれば，使用するルーチングプロトコル は,一つではない. 例えば, IGP (Interior Gateway Protocol) として, あるエリアではOSPF (Open Shortest Path First）を採用し，別のエリアでは EIGRP (Enhanced Interior Gateway Routing Protocol) を利用 する場合もある。このとき，両エリア間でプレフィック ス (prefix)を交換するために再配布 (redistribution)を設 定しているかもしれない. また，外部とのプレフィック

†日本電信電話株式会社 NTTサービスインテグレーション基盤研究 所, 武蔵野市

NTT Service Integration Laboratories, NTT Corporation, Musashinoshi, 180-8585 Japan
ス情報交換と内部への展開にBGP (Border Gateway Protocol）を利用し, 入出力に対する自組織ポリシーを 満足するよう属性值を設定する場合もある。加えて, iBGP (interior BGP) のセッション数削減のためにルー トリフレクタ (Route Reflector, 以後 RR と記す) やコン フェデレーション（confederation）を導入する場合も多 い. また, MPLS (Multi-Protocol Label Switching) を導入し, RSVP-TE (Resource ReSerVation ProtocolTraffic Engineering）により NW のリソースを有効利用 する場合もある。このように，IPNW 上で様々なパケッ 卜転送サービスを提供するためには，様々なプロトコル の設定が必要であり, その複雑さはますます増大してい る.この複雑さを踏まえた上で, NW のルーチング設計, 容量設計, 使用率や遅延など性能の評価をすることが強 く求められている.

プロトコル自体も, その動作は複雑である. RFC (Request For Comments) で定義される複雑な状態遷移 に従ってプロトコルは動作する。また，NWサービスを 良好に, かつ, 矛盾なく行う上で必要な様々な情報を含 む制御パケットが交換される.プロトコル性能評価では, 複雑な状態遷移, パケットメッセージシーケンス, 流通 する情報内容を正確に考慮しなければ，プロトコル性能 を正しく評価することができない. 自律分散処理を特徵 とする IPNW の評価では, プロトコル動作, 交換情報 を正確にモデル化することが不可欠である.

このように， NW，プロトコルの設計・開発では, 複 雑さを避けて通ることはできない. NW 全体を見る視点 でより“精度 (fidelity)” の高いモデルを用いて, NW, プロトコルの設計・評価を行うことが重要になっている. 設計・評価法の一つとして, 離散シミュレーション (Discrete Event Simulation, 以後 DES と記す)があり, OPNET [1], QualNet [2], ns2 などのツールが利用 されている。本論文では, 米国を中心に, 企業, 政府・ 
軍事関係，大学などで広く利用されている OPNET ッー ルについて取り上げる。

本論文では，2.で OPNET の基本的な考え方，全体 像を示す. 3. では, 仮想 NW 環境の概念を示す. 4. では, NW モデルの構成方法の基本について述べる.5. では, プロトコルモデル作成方法の基本について概説する. 最 後に, OPNETを用いた性能評価について整理する。

\section{OPNET の基本的な考え方と OPNET ッー ルの紹介}

OPNETは, OPNET Technologies 社によって開発 されたツールであり， NW 管理・設計に携わる $\mathrm{NW}$ 技 術者, プロトコル開発にかかわる研究開発者にとってデ ファクトスタンダードなツールである。米国を中心に, 世界で利用されている。米国 Cisco 社[3]では, OPNET と自社ツールを組み合わせ, NAPAS (Network Application Performance Analysis Solution) [4]という コンサルティングサービスを提供している.

OPNETには，プロトコル開発用として，DES モデ リング機能を有する Modeler ツールがある. Modeler は，プロトコル設計評価のための階層的なオブジェクト 指向の DES モデリングッールである。ここで述べる階 層とは, NW, ノード, プロセスの 3 階層を意味する. 個々 の階層に対応したモデリング用エディタが完備されてお り，C言語により，プロトコルの詳細動作のプログラ ミングを行う， RFC 準拠の豊富なプロトコルモデルラ イブラリがあり，モデリングにおいて有用な様々な API が完備している.

OPNET には, Modeler 以外にも, NW 設計・管理用 の様々なツールがある. NW, 及び, アプリケーション (以 後 AP と記す）性能評価のための総合管理製品である Service Provider Guru Network Planner (以後 SP Guru と記す), WDM (Wavelength Division Multiplexing）ネットワーク設計用の Service Provider Transport Network Planner，これら二つの層を関連づける SWIM (SP Guru/WDM Guru Integrated Modeling) というッー ルがある。 NW 運用には, コンフィギュレーションとト ラヒックの情報管理データベースである VNEサーバ という製品が用意されている。また, wireless, MPLS, IPv6 などを扱うスペシャルモジュール群が用意され, Modeler とともに用いて, 詳細なプロトコルモデル作成 が可能である。 AP 性能分析用には，APのメッセージ シーケンス測定, ボトルネック分析を行う ACE ッール など，ほかにも多数の製品がある.

本論文では，主に，DES ツールである Modeler に関 する基本事項の説明とケーススタディを扱う。また, 詳 細なプロトコル評価より, むしろ, 実 NW 全体の性能
評価に関心のある NW エンジニア向けに, SP Guruの 中で, NW モデル設計上有用な機能についても, 以下に 簡単に紹介する.

SP Guru では, Modelerにおけるノード，プロセスモ デリング編集機能をオフにし（プロトコル作成, カスタ マイズは不可), DES エンジンのみを利用し, NW エディ タで作成した NW モデルのシミュレーションが可能で ある. 加えて, 下記に述べる NW 管理上必要な機能を 新たに追加している。

まず，コンフィギュレーション情報のインポート機能 がある，NW モデルを構成する場合, 大きく二つの方法 がある。一つは, パレットからノード, リンクオブジェ クトモデルを選択, 画面上に構成し, 各ノードの属性值 を設定，NWとしてDESが実行できるようにモデリン グする方法である。後述のケーススタディにおいて説明 する。一方, コンフィギュレーション情報のインポート 機能では, 主要ルータベンダ (Cisco IOS, Juniper JUNOS [5] など）のコンフィギュレーション情報を読 み込み, 自動的に NW モデルを構成, 設定パラメータ 值をノードオブジェクトの属性值に適切にアサインす る、ほかにも, VNEサーバ上のコンフィギュレーション データからのインポートが可能である. 対象 NW のコン フィギュレーションデータが入手できる場合や，コンフィ ギュレーションの記述に慣れている場合は, コンフィギュ レーションインポートは便利な方法である.

次の機能は, フローアナリシス機能である. DES では, ルーチングプロトコルによるメッセージ情報交換をシ ミュレーションしてルーチングテーブル (Routing Information Base, 以後 RIB と記す）を作成するが，フ ローアナリシス機能では, コンフィギュレーション情報 から DES のようにメッセージ交換をシミュレーション しないで，計算により RIB を作成する。ルーチングプ ロトコル別の RIB，管理用重み付け（administration weight）を考慮して得られる IP 転送用の RIB（フォワー ディングテーブル），エッジ間の経路などを算出する. DES と比較した場合, 収束時間, 故障時の RIB 再構成 動作の確認をすることはできないが, DESより短い時 間で RIB を構成できる点がメリットである。ルーチン グプロトコル動作の過渡状況ではなく, NW の定常時の Reachability や回線使用率のみを把握したい場合には, フローアナリシスは便利な方法である.

また，ネットドクター機能も有用である。ノードモデ ルに設定された属性值をもとに, Python で記述したルー ルエンジンにより，コンフィギュレーション設定の誤り を検出する機能である。実 IPNW の問題では, 設定誤 りが原因である場合が多く，設定誤りを見つけることは 重要である。ルールとは, 例えば, ルーチングプロトコ ルを動作させるために必要な設定上の規則を意味する。 


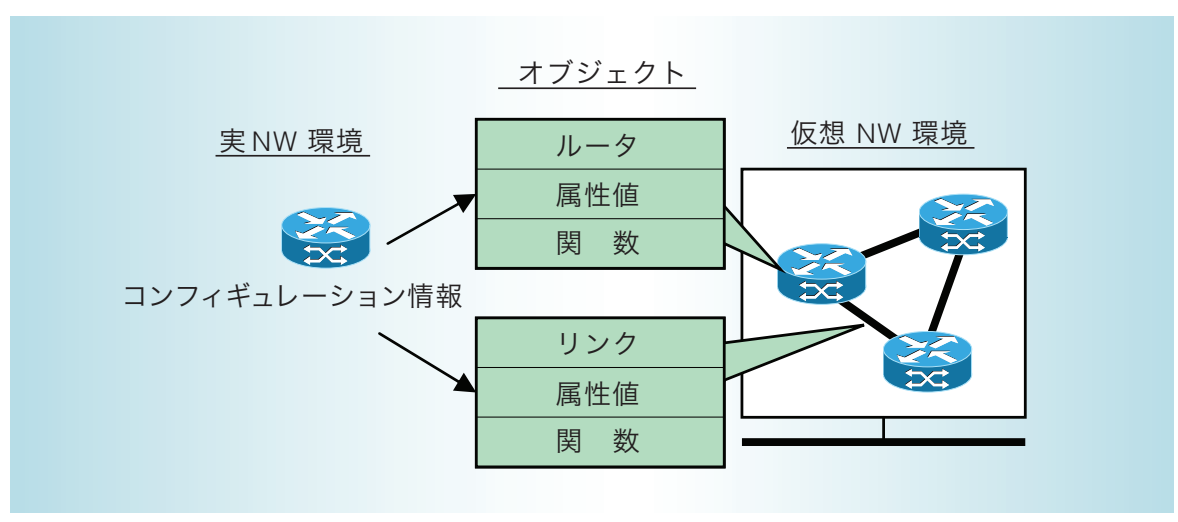

図 1 仮想 NW 環境 $[6]$

NW 上に同じIP アドレスが存在してはならないという 簡単なものから, OSPFであれば，参照带域の設定は， $\mathrm{NW}$ 全体で統一しなければならないというものである. これらについては，文献 [6] のチュートリアルも参考に してほしい.

\section{3. 仮想 NW 環境の考え方}

OPNET のコンセプトを理解するには，仮想 NW 環 境のコンセプトを理解すると分かりやすい. 実 NWや トラヒックの実体（ノード，トラヒックフローデータな ど）を，図 1 のように、コンピュータ上のオブジェクト ヘマッピングし，実環境に近い状況をコンピュータ上で 再現する，実ルータの設定パラメータは，OPNET上の ルータオブジェクトの属性值に, 実ルータ上の動作処理 は, OPNET 上のルータオブジェクトで動作するプロセ スモデルに相当する。このように，実体の特性を抽象化 して，オブジェクトとしてマッピングし，構成された コンピュータ上の NW モデルを仮想 NW 環境と呼ぶ.

仮想 NW 環境を用いた NW 管理のワークフローは, 以下のようになる。（1）現状のコンフィギュレーション データから仮想 NW 環境（以後ベースライン NW モデ ルと呼ぶ)を構成する。(2)コンフィギュレーションの誤 りチェックを実行する。（3）DESを実行し，ベースラ イン NW モデルの RIB やリンク使用率の確認, AP の レスポンス特性などの性能分析を行う。(4) ベースラ イン NWモデルと比較するための様々なシナリオ, コンフィギュレーションモデルを作成する。（5）作成し たシナリオモデルを仮想 NW 上で構築し，What-if test を実行する。（6）複数のシナリオの中から，最終的な NW 設定を決定し，そのコンフィギュレーション内容を 実 NW 環境に適用する。以上のように効率良く体系化 された NW 管理を可能とする。

\section{4. ケーススタディ $1: \mathrm{NW}$ モデルの作成}

$\mathrm{NW}$ シュレーションでは, 対象とする NW のコン フィギュレーション設定に従って，NW モデルを構築す る必要がある。ここでは，大規模な IPNWでよく見ら れるコンフェデレーションを導入した場合を事例に, NW モデルの作成ポイントについて説明する. 本章では, NW モデルの作成方法の基本と IOS コンフィギュレー ションと属性值との関係について理解することを目標と する.

\section{ケーススタディで扱うネットワーク構成}

（1） AS を複数の AS $(65000,65001,65002 ）$ で分割 したコンフェデレーションによる NW 構成を考える（図 6). AS65000では，ルートリフレク夕（RR）を構成し, そのクライアント $(\mathrm{RRC})$ は, RR と $\mathrm{iBGP}$ セッションを 張る.

（2）分割された AS では，それぞれ OSPF が動作 している。

（3）外部 AS $(200,300 ）$ とは, AS65000 の NW と 接続し，自 NW が外部 AS 間のトランジット NW にな らないように，eBGPの AS Path 属性を設定する。

(4) トラヒックフローは, (AS65001, 65002, 200, 300)のルータ間をメッシュで設定する.

[Step 1] OPNET を起動し, 新規プロジェクトを作成 する。 OPNET の初期画面から File $\rightarrow$ New を選択す ると, Wizard画面が現れる。以後,「一」はプルダウン メニューの操作手順を示す。プロジェクト名，シナリオ 名の入力が求められ, 次に NW卜ポロジーの構築方法 が求められる。先に示したインポート機能を用いる場合 もあるが，白紙上にNWを作成する場合は，Create empty scenarioを選択する。次に NW の規模を選択 する。ノード間距離を考慮するためのものであり，世界 地図, 地域図などの様々なスケールが用意されているが, ロケーションを考慮せず接続状況のみを白紙に描きたい 
場合は, Logical を選択する. 次に, NWで使用する 技術の選択画面が現れ，今から作成する NW モデルが 使用する技術を選択する。これにより NW エディタと パレット画面 (図 2) が開く。一度，プロジェクトを作成 した後に再度，NWエディ夕を開くには，File $\rightarrow$ Openで当該プロジェクトを選択する.

[Step 2] パレットは, モデルライブラリを示す。パレッ トから必要なオブジェクトを取り出し, エディタ上で NW を構成する。 ルータ, スイッチなどの機器から構成 されるノードモデル, イーサネットリンクや PPP (Point-to-Point Protocol) 回線などのリンクモデル, ア プリケーションや MPLS などの様々なパラメータ設定 を容易にするユーティリティモデル, MPLS LSP (Label Switched Path) など論理パスを扱うパスモデル, IP 卜 ラヒックフローなどを扱うデマンドモデルがある。 ノー ドモデルでは, ベンダ別, 主要プロトコル別に分類され ている.

ベンダモデルは, 一般モデルをもとに, インタフェー ス数, 処理能力パラメー夕（例えば, Backplane transfer rate, Datagram switching rateな ど）をベンダ製品のスペックに合わせて構成されたもの である。ノードモデルを構成するモジュール構成, 各種 プロトコル動作を記述したプロセスモデルは, 一般のも のと同じである．また，モデル名が例えばrouter_atm_ fe4_slip3_dcという場合は, ATM (Asynchronous Transfer Mode) インタフェースを一つ, Fast Ethernet/ Ethernetのインタフェースを四つ，シリアルインタ フェースを三つ備えたルータノードであることを示す。 これらを参考に NW 設計上必要なノードを選択する。

リンクモデルから，ノード間を接続するリンクモデル を選び，接続するノード間で接続する。注意として，必

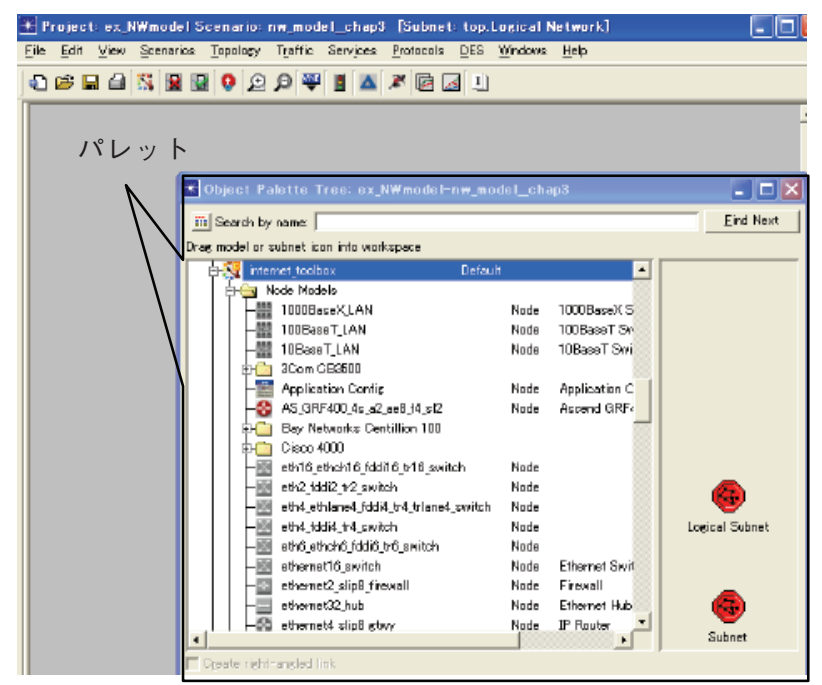

図 2 NW モデル編集エディタの画面例
ずそれぞれのインタフェースのプロトコルに一致する リンクモデルを用いて接続しなければならない.また, 各インタフェースにアドレスを具体的に設定した場合, リンクオブジェクトを介して接続されるノードのインタ フェースとの間で, IP サブネットとして矛盾なく, インタフェース同士を接続しなければならない.リンク オブジェクトの属性值 (Edit Port) から, リンクオブ ジェクトを接続しているノードとそのインタフェースが 表示されるので, この情報をもとに確認する. 図 3 の場 合, node_5のIF15 と node_10の IF17 がリンクモデル で接続されていることを示す。この設定を間違えると， 画面上はノードがつながっているように見えるにもかか わらず，パケットが疎通しないというエラーが起きる。

以上の動作を繰り返してノード間にリンクを接続し, 自分が想定するNW モデルを構成する。ただし，この 段階では, 単純にノード間がリンクで接続されただけで, ルーチングプロトコルやIPアドレスは設定されておら ずNWとしては機能しない.

[Step 3] NW 設計上一番重要なルーチングの設定を行 う. 実際の機器に行うのと同様, IP アドレスのインタ フェースへの設定に始まり，様々なルーチングプロトコ ルのパラメータを, ノードオブジェクトの属性值として 設定していく．ここでは, Cisco IOS のコンフィギュレー ションとの比較をしながら, コンフィギュレーションパ ラメータと OPNET の属性值との関係を明確にする.

[Step 3.1] インタフェースの設定

例えば,インタフェース IF15に, IPアドレス (192.0.4.1)，サブネットマスク（255.255.255.0） を設定する場合, Cisco IOS では, 以下のように設定する。

\section{interface IF15}

ip address 192.0.4.1 255.255.255.0

これに対応するOPNETのルータオブジェクトの 設定は, IP>IP routing parameter>Interface Information 属性值で行う。なお, 属性值は, トリー 構造になっており，「〉」を使って記述する. Interface Information 設定画面には, Name，Status，Address， Subnet mask, MTU (Maximum Transmission

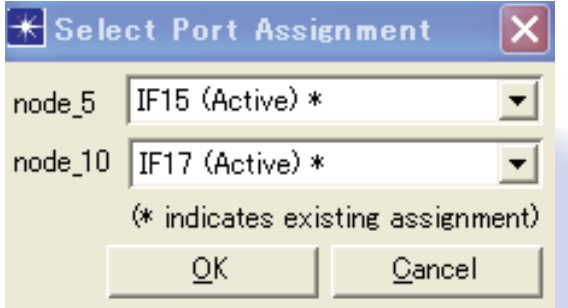

図 3 リンクオブジェクトの属性值表示画面(Edit Port) 
Unit）などの設定項目があり, 各項目について, Name (IF15), Address (192.0.4.1), Subnet mask (255.255.255.0), MTU（IP）と設定する。ほかにも, ルーチングプロトコル, ATM や FR（Frame Relay）を 扱う場合のSub-interface, データ圧縮を定義する Compression, ルートマップなどポリシーの定義を行 う Routing instance, MPLS VPN (Virtual Private Network）を考慮した場合の VRF（VPN routing and forwarding）などの設定項目があり, 対象とする NW コンフィギュレーションに応じて設定を行う．同様の操 作を各インタフェースに対して行う. 注意点として, リン クオブジェクトで対向するノードのインタフェースとの アドレスの関係, リンクオブジェクトのプロトコル とMTUを矛盾なく設定することが重要である. Loopback addressの設定も同様に行う.

[Step 3.2] ルーチングプロトコルの設定 (OSPF 編)

NW にルーチングプロトコルとして, OSPF を設定す る場合, Cisco IOS では, 例えば, 以下の例のように設 定する。

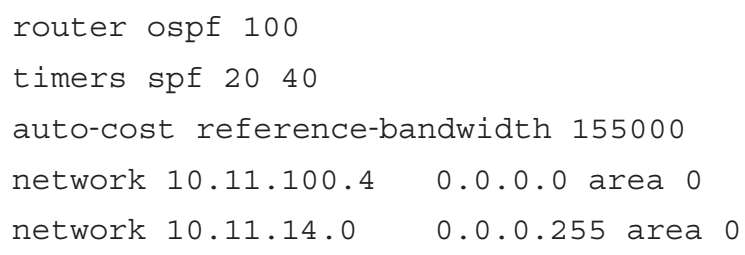

これは以下を意味する。（i）プロセス番号 100 の OSPFを起動させる。（ii） shortest path first を実行す る上でのタイマ值, delay, holdingをそれぞれ 20，40 に設定する。（iii）リンクコスト算出に用いる参照带域 を $155 \mathrm{Mbit} / \mathrm{s} に$ 設定する。（iv）設定している $10.11 .100 .4 / 32 ， 10.11 .14 .0 / 24$ の NWに所属す るインタフェースで OPSF を実行させ，エリア番号を 0 と設定する. NW 上の同じプロセス番号をもつ全 OSPF ルータにおいて, タイマ值と参照带域を一致させておく ことは,いうまでもない.

OPNET の OSPF 属性值との対応は以下のようにな る. IP Routing Protocols>OSPF Parameters から OSPF のパラメータ設定画面が表示される。ここ で, OSPF に必要な様々なパラメー夕を設定することが できる. SPF Calculation Parameters, Reference Bandwidth, Network Informationなどのプロパ ティを用いて, タイマ值, 参照帯域, NWを設定する. 加えて, IP のインタフェース設定画面上で, OSPFが 動作する各インタフェースのルーチングプロトコルを OSPF と設定した後, OSPF属性值の設定画面の Interface Information テーブルを開く. OSPFを 動作させるインタフェースに対し, Status enabled， Areaを0.0.0.0，Tag Numberを100に設定する.
以上が, IOS の記述から OPNET のルータオブジェク トの属性值への設定する方法である.

[Step 3.3] ルーチングプロトコルの設定(BGP 編) 大きな NWを扱う場合 BGP は不可欠である。 NLRI (Network Layer Reachability Information) や Neighbor など, 様々な設定が必要になる。例えば, コンフェデレー ション設定では, Cisco IOS の場合，

router bgp 65000

no synchronization

bgp router-id 100.0.0.1

bgp confederation identifier 100

bgp confederation peers 65001, 65002

と設定をする。この設定では，コンフェデレーション IDは100, 分割したASにおいて, 自 ASのBGP AS 番号は65000, Peer 関係のSub ASは, それぞれ $65001 ， 65002$ である. 非同期設定とし, Router ID は, 100.0 .0 .1 となる.

OPNETの属性值設定では, IP Routing Protocols >BGP Parameters から Global Properties を選択, Confederation Configuration で Confederation の設定（IDを 100， peersを65001，65002）を行い, Address Family Properties 中の Synchronization をDisabledに, 最後にIP>IP routing parameters でRouter ID (100.0.0.1) と Autonomous Number （65000）を設定する.

次に NLRI の設定を行う. Cisco IOS では, network コマンドで，例えば以下のように記述する。

network 192.0.1.0 mask 255.255.255.0

OPNETでは, Address Family Propertiesの 中の Network Reachability Informationの中 でAdress (192.0.1.0), subnet mask (255.255.255.0), 及びルートマップ項目の設定を行 う. Neighbor属性值の設定では, 具体的にiBGP, eBGP のセッション相手を設定する. Cisco IOSでは, 以下のように設定される.

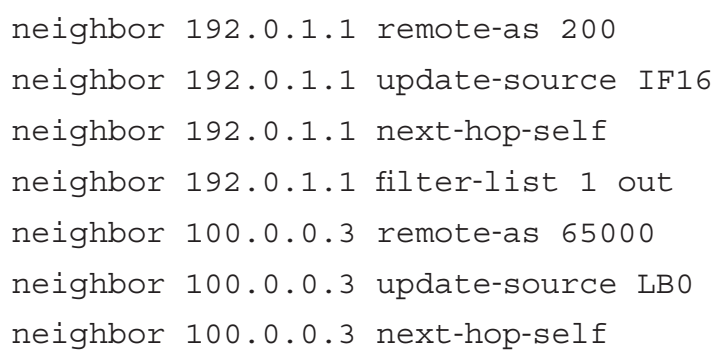

これは, eBGP, iBGP セッションを一つずつ設定して いる事例である。図 4 は, 上記 Neighbor 属性值の設定 に対するOPNETのBGPの属性值の設定画面例を示 


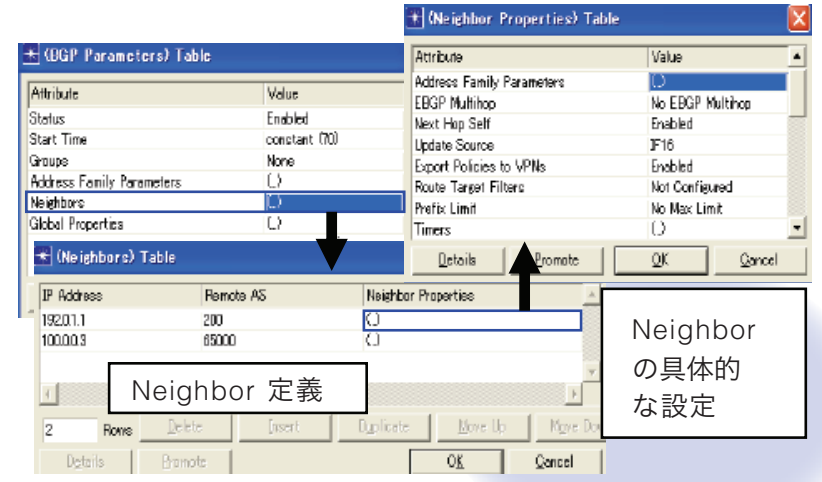

図 4 BGP の属性值の例

す. AS200の NWのうち 192.0.1.1の IP addressを もつインタフェースとの間に eBGP セッションを設定, 自 AS からの NLRI どの情報は IF16 通じて更新 し，自ASのプレフィックスの next hop は，このノー ドであることを示す。番号 1 で定義された Filter List を AS200へ出ていくプレフィックス情報に対して適用す る. OPNETでは, BGP Parameters>Neighbors 70 ロパティの中で, Address (192.0.1.1), Remote AS (200), Neighbor Properties の中の Update Source (IF16), Next Hop Self (Enabled) で設定 を行う. Route Filter の設定は, Neighbors $>$ Address Family Parameters $>$ Route Filters $>$ Send Path Listで1と設定する。例えば, Route Filterとして, AS Path Listに扔いて, 自 AS 番号以外の AS 番号をも つプレフィックス情報を他の ASに通知しないための Filterをかける場合, Cisco IOS では,

ip as-path access-list 1 permit ${ }^{\wedge} \$$

と記述する. OPNETでは, Global Properties>AS Path List プロパティの中で, Match Expression (^\$), Action (Permit) と設定する. OPNETの BGP は，IPv6, VPNv4/v6 などの Address family も対 応している。

以上, Cisco IOS のコンフィギュレーションとの対比 で属性值設定方法の説明をした，NW 設計経験者であれ ば， NW モデル作成において，コンフィギュレーション 情報を属性值に設定していく様子が, 実践的であること が理解できたと思う。

NW 設定の可視化は, View $\rightarrow$ Visualize Protocol Configuration から, IP Routing Protocols(IPv4, IPv6), BGP Peers, OSPF Area Configuration 選択することで，画面上に設定状態を表示できる。この 情報は初期段階の誤り発見に役立つ。更に詳細な誤りを 検出するにはネットドクター機能が便利である [6]，大 きな NWでは, コンフィギュレーション情報を取り込
み，NW モデルを自動構築するインポートモジュールや $\mathrm{VNE}$ サーバを利用する方法が有効である。シミュレー ション後にRIB を確認するためには，ルータノードの 属性值である Reports プロパティで, 該当するルーチン グプロトコルに対し，Exportを指定する。なお， IOS コマンドと OPNET でのサポート状況の詳細について は, OPNET のホームページで確認できる（注: ユーザ ID とパスワードが必要).

[Step 4] トラヒックフローの設定

NW 管理設計のためには, Cisco Netflow な゙を用い たプレフィックス間の交流トラヒック (以後, デマンド トラヒックと記述する）量の測定が必要になる。 ある リンク容量を増大させると, ルーチングプロトコルに 従って, 転送ルートが変化する可能性があるため, NW 全体を見てリンク容量設計を行う必要がある。測定され たデマンドトラヒックをモデル上にインポートすること も可能である。ここでは, 様々な要因 (ユーザ数の推移, 新規サービス開始など）を考慮して推定されたデマンド トラヒックを考える．推定デマンドトラヒックを考慮し たトラヒックシナリオを, モデル上に展開する方法につ いて述べる. 更に, RIB 作成のために必要な制御パケッ 卜を厳密にシミュレーションするが, 転送されるデータ パケットに関しては，下記に示すトレースパケットに代 表させ, リンクの使用率などを算出する, ハイブリッド 型DESについて説明を行う。これは，すべてのパケッ トごとにシミュレーションする詳細な DES に比べると 精度は落ちるものの, 転送ルートと各リンクにかかる負 荷を短時間で推定可能な, 解析手法と DES を組み合わ せた方法である。

デマンドトラヒックオブジェクトは, 発着アドレス, 設定した時間間隔でのビットレート (bit/s), パケット レート (packet/s) の時系列データなどを属性值としても つ. DES 上では, 発アドレスから, bit $/ \mathrm{s}$, packet $/ \mathrm{s} の$ 情報をもつトレースパケットを送信する。これを受け 取ったリンク, ノードオブジェクトは, 統計量としてこ の分のトラヒック量 (送受信トラヒック量, リンク使用 率）を計算する，各ノードではこのトラヒック量に応じ て簡単な待ち行列モデルによる待ち時間情報を統計量と して計算する。厳密な DES 動作によって構築された RIBに従い，着アドレスノードまでトレースパケットは 送達される。

具体的にデマンドトラヒックを設定する．NW のすべ てのエッジルータを選択し, Traffic $\rightarrow$ Create Traffic Flows $\rightarrow$ IP Unicast…を選択すると, Traffic Create 画面 (図 5) が開く。ここでは, 簡単のた めにすべてのエッジルータ間でフルメッシュに設定さ れた，デマンドトラヒックフローを考え，すべて同じ トラヒック量をもつものとする。図 5 にあるように, 


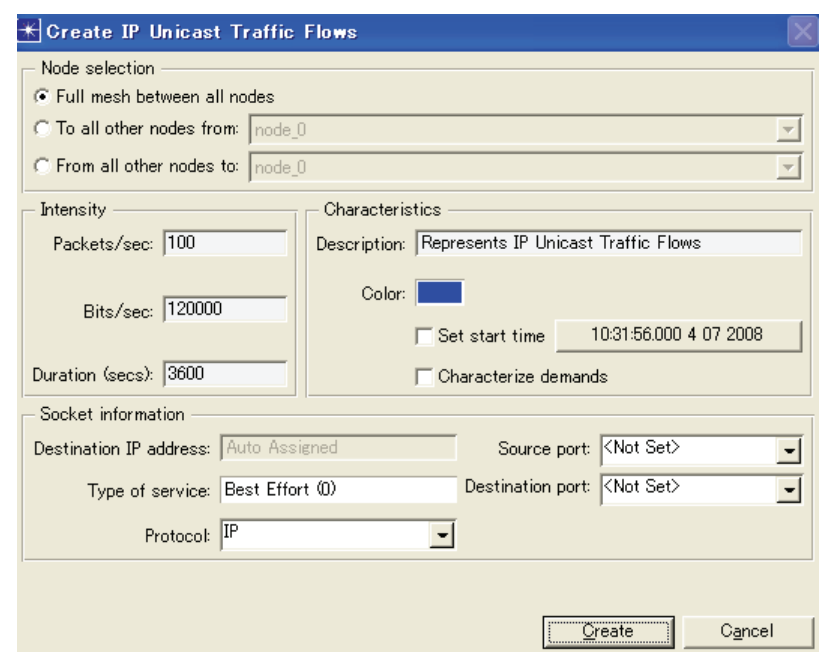

図 5 Traffic Create 画面

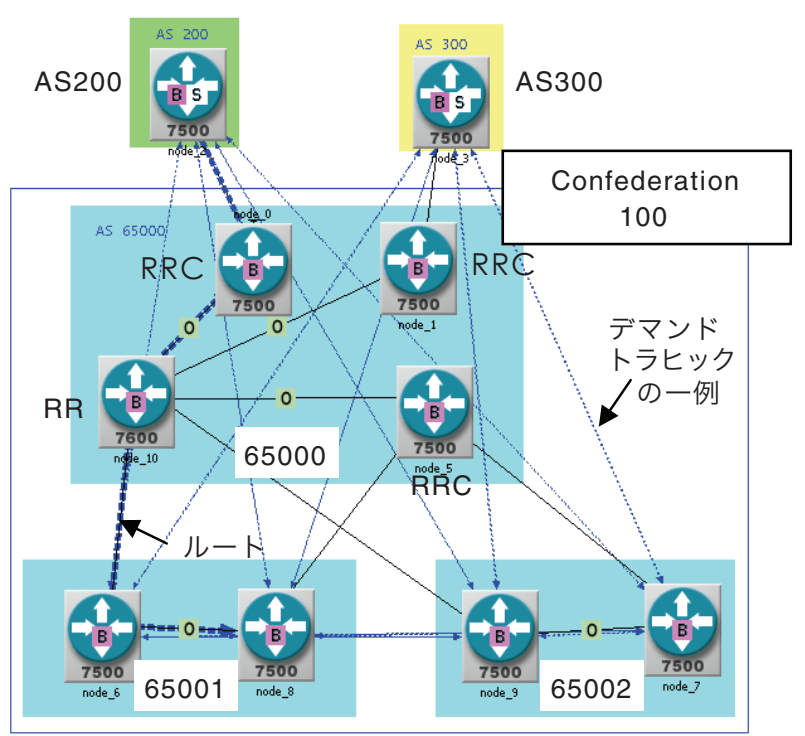

図 6 デマンドトラヒックの経路(ルート)の一例

Intensity，ToS，Protocol を設定できる. Create ボタンを押すと, 画面上に青色点線で, デマンドトラヒッ クフローのオブジェクトが現れ，トラヒックが設定され たことを示す(図 6).

[Step 5] シミュレーション (What-if test)の実行

DES $\rightarrow$ Choose Individual Statistics 定項目を設定し, Run Discrete Event Simulationでシミュレーションを実行する。各リンクの使用 率，RIB，デマンドトラヒックの経由するルートなど, 設定した統計量を確認する。経由ルートの表示 (Protocols $\rightarrow$ IP $\rightarrow$ Demands $\rightarrow$ Display Routes for Configured Demand $\cdots)$ では, DESの終了時点に おけるトラヒックフローのルートが示される(図 6 では, 青色の太い点線で，矢印により「ルート」と示したものが これに相当する)。設定した測定項目は，DES $\rightarrow$
Results $\rightarrow$ View Results から確認，グラフ表示が できる.

以上，OPNET のモデルライブラリを用いた NW モ デルの構成，DES 実行に関する方法のポイントについ て簡単に説明した。ほかにも多くの機能をもつノードオ ブジェクトがあり，それぞれ DES を実行するための設 定方法があるが，ここでは割愛する．OPNET のライブ ラリにあるプロトコル機能をカスタマイズする場合，新 規に開発するプロトコルについて評価する場合は，自ら モデルを構築する必要がある。

\section{5. ケーススタディ 2 : プロセスモデルの作成}

プロセスモデルの基本的な作り方を説明するため， 卜 ラヒックソースモデルの一例として，5.1で示す簡単な 機能をもつパケット送信・受信モデルを考える. 次に, 5.2 でノードモデル作成について述べる. 更に, 5.3 で, プロセスモデルの作成ポイントについて説明する.特に, プロセスモデル間の親子関係，ICI の使い方について説 明し，デバックモードで動作させ，エラーを検出，対処 する事例を示す。

\section{1 ケーススタディで扱うモデル}

（1）プロセスモデルの概念の説明が目的であるた め, TCP, IP, MAC などのプロトコル内部処理の説明に は踏み込まず，単純にパケットを送受信するプロセスモ デルのみをここでは扱う。

（2）送信側のマネージャプロセスは，複数の子プロ セスを生成，これを管理する。生成された子プロセスは， それぞれ，生存時間中パケットを送信するトラヒックフ ローに相当する，子プロセスは生存終了時間に到達する と，マネージャプロセスに，そのプロセス番号とプロセ スの終了を割込み通知する。

（3）受信側は，到着したパケットを受信する機能を もつ.

\section{2 ノードモデルの作成}

ノードモデルを構築する場合，ノードモデルエディタ から, Process, Queue, Transmitter, Receiverなどを意 味するモジュールを，プロトコルレイヤ構成に従って組 み合わせ，それぞれのモジュール間を矢印で結び，ノー ドモデルを構築する。各モジュール間の情報流通方法に は, (a)パケット, (b) 割込み, (c) ICI (Interface Control Information, 説明は後述) の 3 種類がある。ノード モデル中の矢印はパケットの通り道を意味する。 Interfaces $\rightarrow$ Node Interfaces から，ノードモデ ルに関するプロパティを設定できる。複数のシミュレー ションモデルと協調シミュレーション (co-simulation)を 行う場合やトレース時間をもとにシミュレーションをす る場合, OPNET と外部プログラムを連携する必要があ 


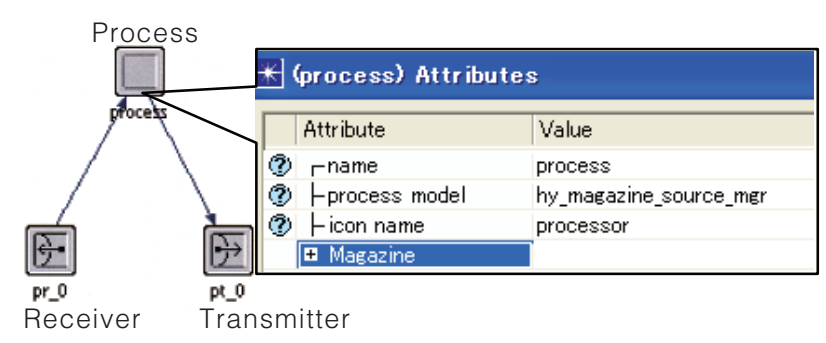

図 7 送受信ノードのノードモデル

る.この場合, ESYS (External SYStem)API 用モジュー ルを用いてノードモデル設計する。 co-simulation など 外部プログラムとの連携は, 基本事項の範疇を超えるの でここでは説明しない.

図 7 にケーススタディで扱う送信側ノードモデル構成 を示す. Process, Transmitter, Receiver モジュールを 組み合わせた単純なモデルである. Process モジュール では，下記で作成するプロセスモデル（hy_magazine_ source_mgr)が動作するように属性值を設定する.

\section{3 プロセスモデルの作成}

プロトコルや制御手段を評価する場合，本質となる コントロールプレーンの処理動作をできる限り忠実にモ デル化する必要がある。そのためには，(i)考慮すべきプ ロトコルの状態遷移図，（ii）状態遷移するタイミング, （iii）交換する情報内容とその交換手段，を明確にモデル 化することが重要である。モデル化のワークフローは, 以下のようになる。（1）検討対象のプロトコルついて十 分分析する。（2）状態遷移図を作成する。（3）作成した 状態遷移図をもとに, OPNET 上で状態遷移図を作成す る。（4）遷移条件や定数などを定義する．（5）具体的動作 をプログラミングする。（6)コンパイルリンクし, デバッ ガを利用してバグを検出する．問題があれば，(5)に戻っ て修正し，モデルを完成させる。

[Step 1] OPNET 上で状態遷移図を作成

この単純なケーススタデイモデルは，パラメータの初 期化を行う Init 状態, 待機状態の wait 状態, 及び, パケットを送信するトラヒックフローを生成する子プロ セス（hy_magazine_simple_source）を起動する spawn 状態，同プロセスの終了管理を行う clear 状態 の四つの状態から構成される。プロセスモデルの状態遷 移図を, 図 8 に示す。この管理プロセスから起動される 子プロセスの状態遷移を図 9 に示す。説明上分かりやす くするために，両図中で，状態名には下線を引いている。 また, (遷移条件マクロ名)/遷移時の動作関数，の形式で 遷移条件と動作を示す。子プロセスは, 初期化（Init 状態)の後, generate 状態でパケットを生成, 送信する. 子プロセスの生存時間は, 属性值で設定した確率分布に 従う。子プロセスの生存中は, 属性值で設定された確率 分布に従う送信間隔でパケットを送出する。生存時間が

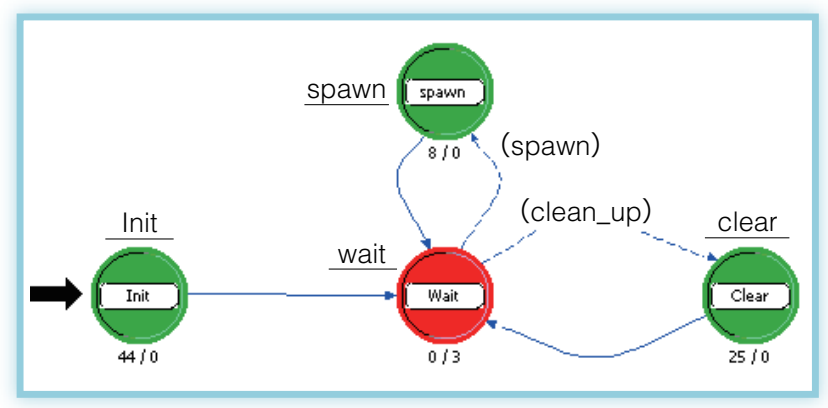

図 8 マネージャプロセスモデルの状態遷移

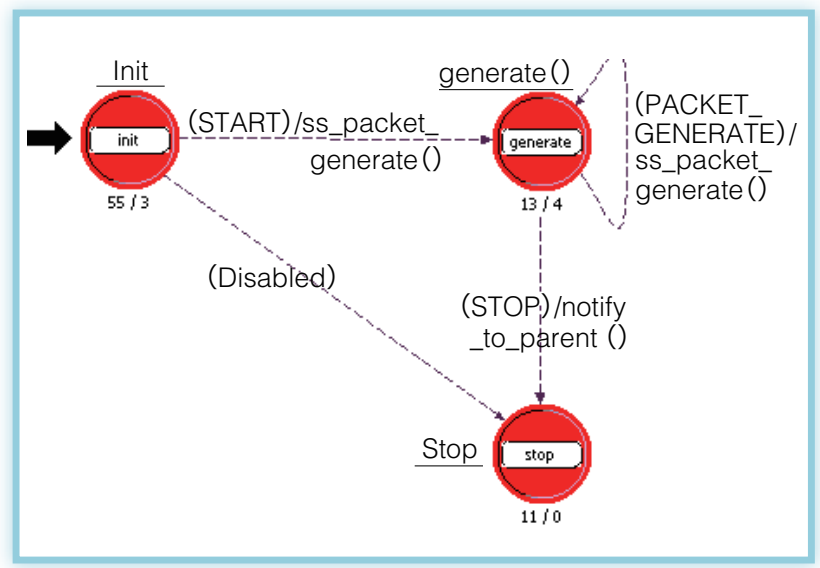

図 9 子プロセスモデルの状態遷移

終了すると, stop 状態に遷移，マネージャプロセスに 終了を告げる。

状態には, Unforced (赤色) と Forced（緑色）の 2 種 類がある. Unforcedでは, 状態遷移時点で, 状態に入 る際に定義した処理（enter exec）を行い, DES カーネ ルからの割込み待機状態になる。割込み受信後直ちに, 状態を出る際に定義した処理 (exit exec) を行う。一方, Forcedでは，状態に入る際に, enter execを行い, DES カーネルからの割込み信号を待つことなく直ちに exit exec を実行，状態を出る。今回，親プロセスは， wait 状態のみ，子プロセスはすべて Unforced である. wait 状態では，遷移条件に相当する DES カーネルか らの割込みを待つ. 親プロセス内で定義した，次の子プ ロセスの起動スケジュールによる割込み通知があった場 合は，spawn 状態へ遷移する，生成した子プロセスか らの割込み通知の場合, clear 状態へ推移する.

次に，遷移を示す矢印には，実線と点線がある。実線 は, 確定的にこの線に沿って状態が遷移することを示し, 点線は, 状態遷移条件が真の場合に, その矢印に沿って 状態が遷移することを示す。したがって，ある状態から 複数の状態のいずれかへ遷移する可能性がある場合, そ れぞれについて，遷移条件を定義する，㚈終了，パ ケット到着, 内部割込みなどが遷移のトリガとなる。状 態遷移図は，検討対象のプロトコル動作を分析し，どの 
ような状態が考えられ，どのようなトリガのときに何を 行うか，次にどの状態に推移するかを Forced/Unforced 状態モデルと実線/点線による矢印によって表現する。

[Step 2] HB (Header Block)の構築

プロセスモデルエディタには, ヘッダ情報, 変数, 関 数を定義するテキスト画面がある. [Step 1] で定義した 状態遷移条件の具体的なマク口定義のほかに，必要な include fileの宣言，このプロセスモデル内で用いる割 込みコード值の定義，FB（Function Block）で定義する 関数の宣言などを $\mathrm{HB}$ で定義する。変数については, SV (State Variables), TV (Temporary Variables) で 定義し，HBで宣言した関数のプログラムを $\mathrm{FB}$ で記述 する.

[Step 3] プロトコル動作のプログラミング

enter/exit exec，及びFBでは，OPNETのAPIを 利用し， C 言語を用いて，検討対象となるプロトコル動 作をプログラミングする。ここでは，プロセスモデルの 親子関係と ICI の概念を中心にパケット処理，割込み処 理に関する OPNET APIについて説明する。

[Step 3.1] プロセスモデルの親子関係を表現する API

セッションの全体管理と個々のセッションのパケット 送受信動作の記述を，一つのプロセスモデルで記述する と複雑になり，モデリングを理解，拡張する上で，効率 的でない. OPNETでは, 図 10 に示すように子プロセ スを起動 (invoke) させることができる，生成される子プ ロセスの管理と個々のセッション動作を示す子プロセス を別々にモデリングする方が，プログラム上管理しやす い. 子プロセスの作成は, 以下の API を利用して記述 する.

（i） op pro_create（プロセス名, 引数情報への ポインタ)でプロセスハンドルを作成する.

(ii) op_pro_invoke（プロセスハンドル名, op_pro_argmem_access（）でアクセス可能な情報へ のポインタ)で, 子プロセスを起動する.

例えば，今回のモデルでは，マネージャプロセスが

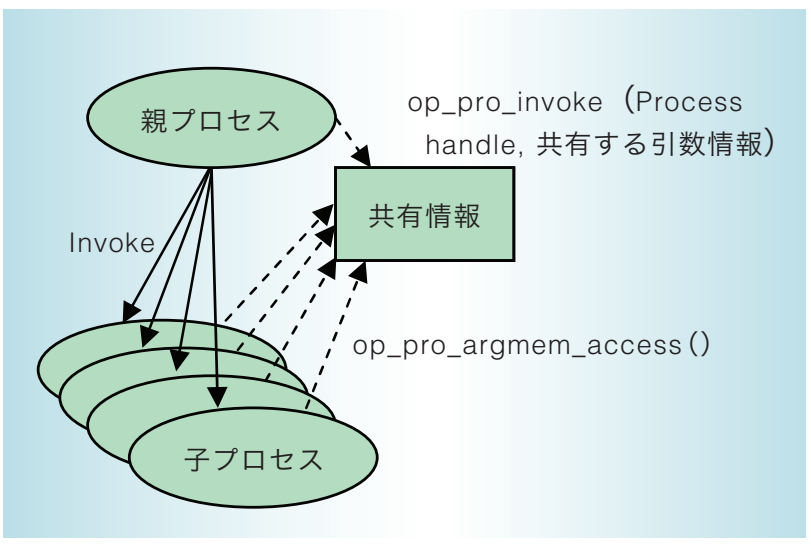

図 10 プロセスの親子関係 [6] spawn 状態に入ったときに，以下の記述で子プロセス を起動させる。

flow_prohndl $=$ op_pro_create

(“hy_magazine_simple_source", OPC_NIL)

プロセス名がhy_magazine_simple_sourceの子プ ロセスハンドル（flow_prohndl）を定義する．次に，

op_pro_invoke (flow_prohndl,

$$
\text { flow_ptc_mem_ptr) ; }
$$

で, 情報共有する構造体（flow_ptc_mem_ptr）を引数と して子プロセスを起動する。プログラム中で用いる構造 体の定義は，HBの中，または，ヘッダファイルを作成 して定義する。プロセス間の情報共有を可能とするため の API も用意されている。

(iii) op_pro_argmem_access APIを用いて, 子プ ロセスは, 親プロセスの指定した情報へアクセスできる. この事例では，子プロセスは，flow_ptc_mem_ptrに アクセス可能であり, 親プロセスと情報共有できる.

(iv) op_pro_modmem_install APIを用いて, 同 じモジュール内の他のプロセスと共有できる情報を指定 する.

(v) op_pro_modmem_access APIを用いて, (iv)で インストールされた共有情報にアクセスできる.

[Step 3.2] パケット処理と ICI 処理の API

プロセス間の情報交換手段は，主に，パケットと ICI による方法がある，パケットによる情報交換は，パケッ トフィールドを用いる。これに情報を付与し，受け手が アクセスすることで情報を得る。一方，内部のプログラ ム間の割込み処理による情報交換では，パケットではな くICIを用いる。この事例では, magazine_iciを定 義する，OPNETでは，パケット，ICIについて，それ ぞれ構造を定義するエディタがある。図11はICI エ ディタの例で, invoked_pro_id という名前の属性值 (integerタイプ) 一つから構成されるICIを定義して いる.

主なパケット処理に関する API を, 以下に示す。

(i) op_pk_create_fmt（パケットフォーマット) で，パケットを生成する。

\section{* ICI Format: magazine_ici}

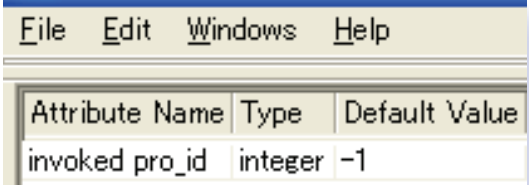

図 11 ICI エディタ画面(一部) 
(ii） op_pk_nfd_set（パケットポインタ, フィー ルド名, 值)で, パケットのフィールドに值を設定する。

(iii） op_pk_send（パケットポインタ，送信先の Stream Index(ノードモデル上で, 次に送信するモジュー ルへの矢印の ID)) でパケットを送信する.

(iv) 受け側は, op_pk_get（パケットを受け取っ た矢印の ID)により，パケットポインタを受信する.

(v) op_pk_nfd_access（get）（パケットポイン 夕, フィールド名, 值) で, パケットのフィールドの設 定值を取得する。

(vi） op_pk_destroy（パケットポインタ）で，パ ケットを廃棄する。

ICI は，パケットに似たデータオブジェクトであり， プロパティにデー夕を入力できる。様々な割込みに付随 させて，この情報を割込み先に通知する. 主な ICI 処理 に関する API を以下に示す。

(i) op_ici_create（フォーマット名）でICIを作 成する。

（ii） op_ici_attr_set（ICIのポインタ, 属性值名, 属性值)で，必要な情報を設定する。

（iii） op_ici_install（ICIのポインタ）でICI 情 報をインストール(通知可能に)する。

（iv）割达み処理を実施する.

（v）割込みを受けた側は, op_intrpt_ici（）で ICI ポインタを取得する.

（vi） op_ici_attr_get（ICIのポインタ, 属性值名, 属性值)で, 属性值のデー夕を取得する。

(vii) op_ici_destroy（ICIのポインタ）でICIを 廃棄する。

ケーススタディモデルでは, 子プロセスの終了時に, 親プロセスに対し, ICI を用いて子プロセスのプロセス 番号の通知を行い, generate 状態から stop 状態に遷 移する. ICIの定義と実行は以下のように行う.

(a) magazine_iciとそのプロパティを定義する. ici_ptr = op_ici_create ("magazine_ici") ;

（b）プロパティの設定值としてプロセス ID をセット する。

.

op_ici_attr_set (ici_ptr, “invoked pro_id”, P_to_C_mem_ptr->pro_id) ;

（c）親プロセスへの割込みに付随して ICI 情報が送信 できるようにするｏp_ici_install（ici_ptr）；

[Step 4] プロセスモデルのコンパイル

プロセスモデルを構築後, コンパイルを行う.メニュー の Compile Code, または, コンパイルアイコンから コンパイルを実行する。図 12 は，誤りがあった場合の 事例である.コンパイルを失敗すると Compilation failed を示す画面が開き, エラー箇所を示すリストが 表示される。これをもとに，誤りを探す．今回は， clear 状態で用いた変数 flow_invoked_info_ptrが 変数として定義されていないことを示すエラーである.

TV (Temporary Variables) 内にこれを定義し, 再度 コンパイルすると, Done と表示された画面が開き，コ ンパイルが成功する。

[Step 5] ネットワークモデル上での実行とデバッグ モデル上利用するすべてのプロセスモデルをコンパイ ルリンクし, NW シミュレーションとして動作すること を確認する。 OPNETのデバッガッール（OPNET simulation DeBugger：ODB）を利用する。扱うケース スタディの NW モデルは, 図 13 のように非常に単純な モデルである.magazine_node では, トラヒックフロー 動作を行う複数の子プロセスが発生し, 生存時間中, パ ケットをsink_serverに送信する単純なモデルであ る.

\subsection{ODB (OPNET デバッガ) の動作}

シミュレーション実行画面で, 図 14 のように ODB 使 用を宣言する。シミュレーションを実行するとコンパイ ルリンク処理がなされ, 0 時点の DES の最初のイベン

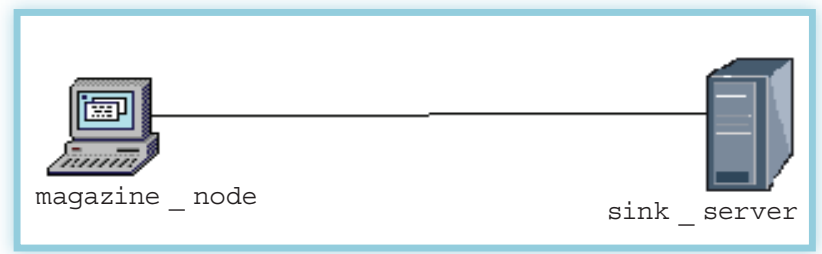

図 13 ケーススタディの NW モデル

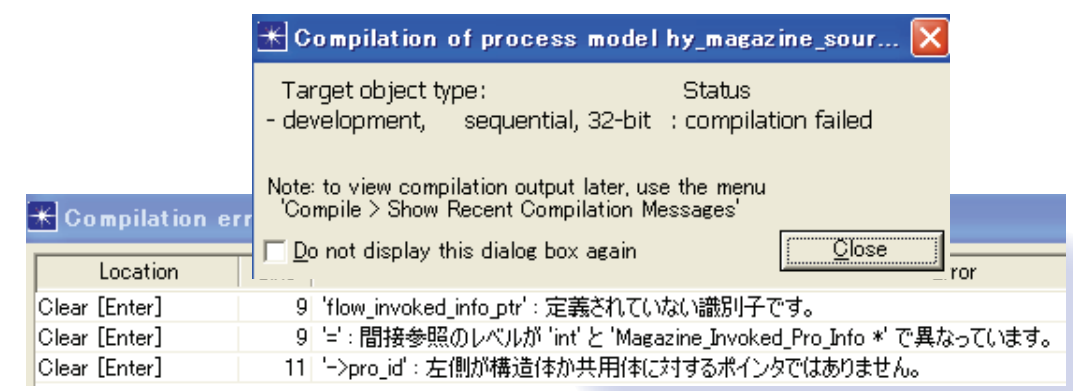

図 12 コンパイルエラーのときの表示例(一部) 
トを待つ状況まで処理が進む.コンソール画面の「ODB の部分に, ODB コマンドを用いて, DESのイベントの 進行を制御できる。また，プログラム中にラベルを定義 できる。ラベルを指定してシミュレーションを実行させ ると，プログラム中で指定した情報をコンソール画面に 表示できる. 今回, magazineというラベルを以下のよ うにプログラム中で定義した。

ltrace_flow_source_mgr_active= op_prg_odb_ltrace_active ("magazine") ;

ラベルを指定し， 30 シミュレーション時点までイベン トを進めるための ODB コマンドは以下のようになる。

ODB>ltrace magazine（magazine ラベルを指定） ODB>tstop 30 （30 時点でイベントをストップ） ODB >C （30 時点までシミュレーションを実行）

プログラム上にエラーがあると，実行途中で以下のよう な画面が現れる。コンソール画面にも, Program Fault, Program Abortの画面が表示される.

このエラー解決のかぎは，画面（図 15）とコンソール 画面（図 16）で示された情報である. 今回の Program Abortの直接原因は, Invalid Memory Accessであ ることが読み取れ，その場所は, magazine_nodeオブ ジェクトの中の Process モジュールであること，また， op_pro_invoke コマンドに問題があることを画面は示 している.コンソール画面では, Function として, hy magazine_simple_source [init enter execs] と記述がある。これは，親プロセスが起動した子プロセ ス (hy_magazine_simple_source)の初期状態（Init

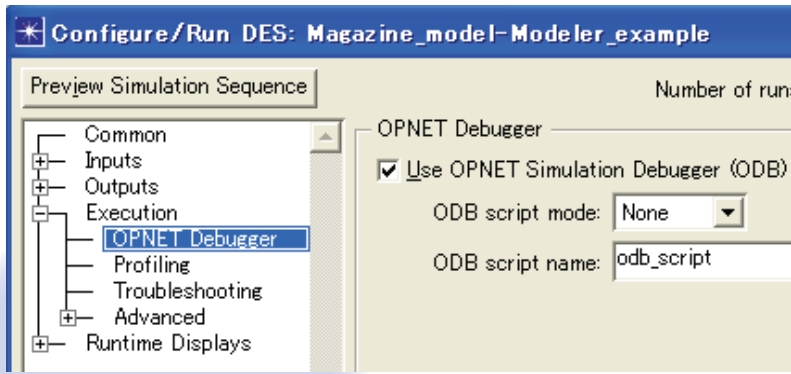

図 14 ODB 実行を指定する画面(一部)
状態）で, 親プロセスと共有する情報メモリに, アクセ ス処理の部分に問題があることを示す。エラー表示内容 から，問題は，親プロセスが，共有情報メモリを正しく 引数として定義しているかどうかに問題があると推測で きる。実際，親プロセスを確認すると，

op_pro_invoke (flow_prohndl, OPC_NIL) ;

とコーディングされており，子プロセスがアクセスする メモリポインタを示していなかった。これを，

op_pro_invoke(flow_prohndl, flow_ptc_mem_ptr) ; と修正することで，エラーは解消される．DES は実行 され，図 17 のような，経過時点におけるアクティブフ ロー総数の計測とこの結果のグラフを作成できる。これ は，ある時点で同時に動作している子プロセスの数を意 味する. sink_serverにおける受信パケット数など, これ以外にも検討に必要な統計量を登録，測定可能であ る.

ODBには，逐次イベント処理結果をトレースするコ マンドや，プロセス，ノードなどのオブジェクト番号を 表示するコマンドなど，様々用意されており，これらを 用いてモデルの誤りを検出，修正することができる。

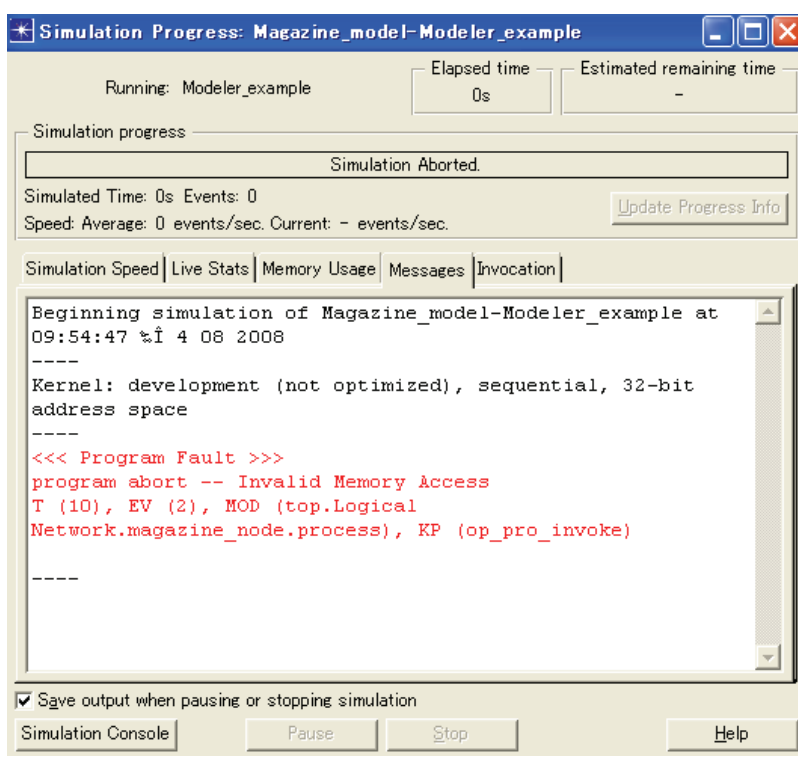

図 15 エラー表示画面

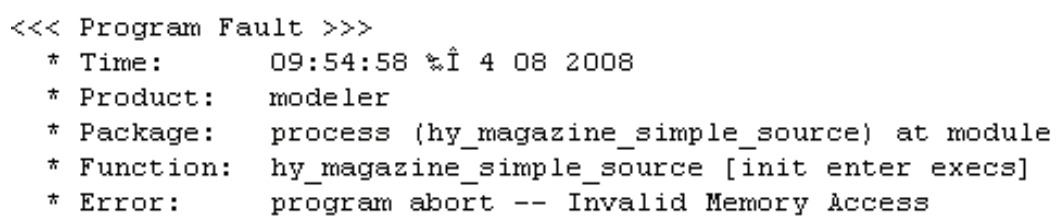

図 16 エラー表示したコンソール画面 


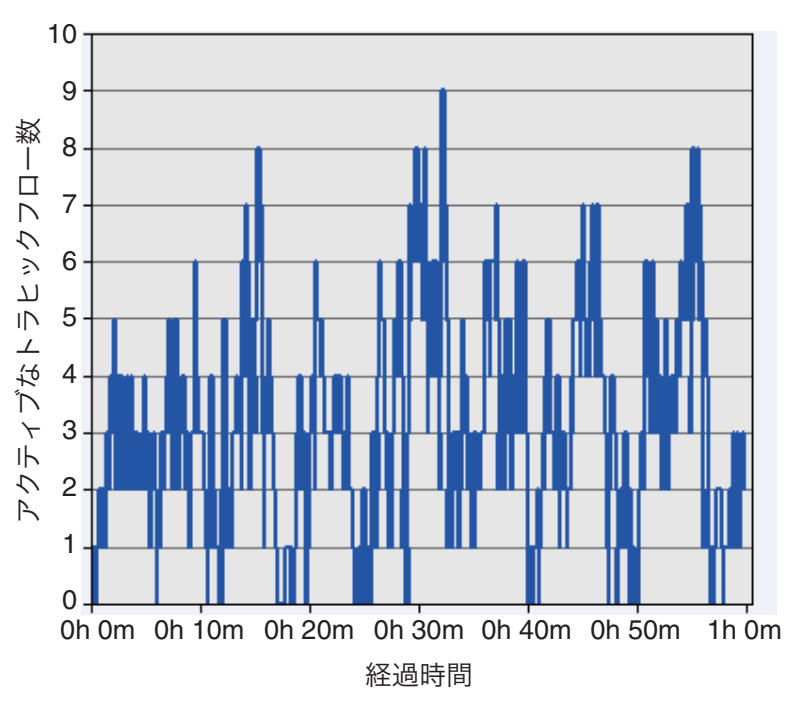

図 17 アクティブフロー数の推移

紙面の関係で, 統計量, プロセスモデルインタフェー スの設定, その他重要な APIについての説明は割愛す るが, 基本的には, 上記で示したワークフローに従って, ノード，プロセスモデルを作成する，オンラインマニュ アルから API や ODB の詳細を知ることができる。カ スタマイズしたプロトコルを OPNET 上のライブラリ モデル，例えば，IP プロトコルモジュールと整合性を とって動作させるには, IP モジュールの内部動作と IP のプロトコル動作をよく理解した上で，モデルを作成す る必要がある $[6]$.

\section{6.むすび}

OPNET のモデリング，利用方法に関する基本内容に ついて説明した。 IPNW 上のプロトコル性能評価では, コントロールプレーンを表現する「 $\mathrm{NW}$ 上の各ノードが, どのような情報を，どのようなタイミングで交換し，そ れに対応して，どのような状態遷移をして，動作を行う か？」を明確にすることが不可欠である。また，様々な $\mathrm{NW}$ 構成の上で, 検討対象のプロトコルが動作すること を証明しなければならない. OPNET モデリングはこれ を可能とする。また，NW 管理ツールして，実際のコン フィギュレーションに応じて NW モデルを構築，様々 な設定, 障害, トラヒックシナリオをもとに What-if testの実行環境を構築できる。

OPNET のホームページには，有用な参考資料が豊富 にある（注：一部アクセスにアカウント，パスワードが 必要)。また，NW モデリングには，コンフィギュレー ションの知識は必須である. Ciscoのホームページ [3] など, コンフィギュレーション事例も豊富で参考になる。 [7]，[8]は，参考書であり，[8]は OPNET の練習問題集
である（ただし記載されているバージョンは，現在のも のより古い).

ここで記述した内容は OPNET の基本事項のごく一 部である. OPNETで実践的なプロトコルモデルを作成 するには，モデル構築の経験を積むことが重要なことは いうまでもない。最後に，これから OPNETを用いて プロトコルや NW のモデリングを試みようとする人に 少しでも扮役に立てば幸いである。

[注意事項 $]$

文章中に記載されているシステム名，商標名は，その 開発元の商標または登録商標であり，この資料では，解 説説明を行う目的でのみ，商品名などを記載している. その商標権を侵害する意思, 目的のないことをここに, 申し述べておく. OPNET のモデル紹介はVer.12をも とに解説をしている. OPNET のバージョンは, 毎年上 がるため, 今回の説明部分について, 別バージョンでは, 変更されている場合もあることを御了承頂きたい.

文献

[1] OPNET Technologies, Inc., http://www.opnet.com

[2] Scalable Network technologies, http://www.qualnet.com/

[3] Cisco Systems, http://www.cisco.com/

[4] Cisco Network Application Performance Analysis (NAPA) Solution, http://www.cisco.com/en/US/prod/ collateral/netmgtsw/product_promotion0900aecd8039e0 64.html

[5] Juniper networks, http://www.juniper.net/

[6] 山田博司, “OPNETを用いたネットワーク・プロトコルの 性能評価について,”信学技報, NS2008-5, 2008.

[7] L. L. Peterson and B. S. Davie, Computer Networks - A System Approach, 3rd ed., Morgan Kaufmann Publishers, San Francisco, 2003

[8] E. Aboelela, Computer Networks - A Systems Approach, 3rd ed., Network Simulation Experiments Manual, Morgan Kaufmann Publishers, San Francisco, 2003.

(URL は，執筆時 $(7$ 月 28 日) 確認のものである.)

(平成 20 年 5 月 14 日受付, 7 月 28 日再受付)

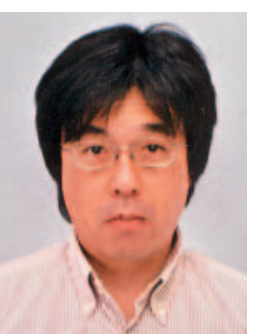

山田 博司 (正員)

昭 60 名大 $\cdot$ 理 $\cdot$ 数学卒. 同年日本電信電 話株式会社通信研究所入所. 通信ネットワー クの性能評価・シミュレーションモデリン グ技術の研究開発に従事。平8東京工業大 学・博士 (工学). 2000, 2002, OPNETWORK Distinguished Paper Award, 平 19 年度ネットワークシステム研究賞受賞. 